\title{
The energy spectrum and phantom image quality according to mammography target-filter combinations
}

\author{
Seyoung Jang, Wanggyun $\mathrm{Oh}^{*}$, Jongbae Park ${ }^{* *}$ and Gyehwan Jin \\ Nambu University, Chungbuk National University", Chungbuk Health \& Science University ${ }^{* *}$

\section{유방촬영장치의 타깃에 따른 에너지스펙트럼 및 팬텀영상화질}

\author{
장세영, 오왕균 ${ }^{*}$, 박종배**, 진계환 \\ 남부대학교, 충북대학교*, 충북보건과학대학교**
}

\begin{abstract}
When the $X$-ray energy is high, the $X$-ray penetrates the object and decrease the contrast of imaging, and when the $X$-ray energy is low, the $X$-ray increases the contrast of imaging but it is to be absorbed into the object, which in the long run increases patient's radiation exposure level. Therefore, appropriate $\mathrm{X}$-ray energy is an essential element affecting the imaging quality and radiation exposure level. This study simulated the energy spectrums according to the target materials of mammography, and compared qualities of phantom imaging for the management of radiolographic quality and patient's radiation exposure level with the introduction of the mammography that employs diversified radiation quality by using new anode materials.
\end{abstract}

Key Words : mammography, target-filter, energy spectrum, image quality

\section{요야}

엑스선의 에너지가 높으면 엑스선이 피사체(object)를 통과하여 영상의 대조도를 떨어뜨리고 엑스선의 에너지가 낮 으면 영상의 대조도는 증가시키지만 엑스선이 피사체에 흡수되어 환자의 피폭선량을 증가시킨다. 그러므로 적정한 엑 스선 에너지는 영상의 질과 피폭선량에 영향을 미치는 매우 중요한 요소이다. 본 논문에서는 새로운 양극물질을 사용 하는 유방촬영 장치의 도입에 따라 방사선 선질이 다양해진 유방촬영장치의 영상품질관리와 환자선량관리을 위하여 유방촬영장치의 타겟 물질에 따른 에너지스펙트럼을 시뮬레이션하고 팬텀 영상의 화질을 비교하였다.

중심단어: 유방촬영장치, 초점-필터, 에너지스펙트럼, 영상품질

\section{I. 서론}

세계보건기구(WHO) 산하 국제암연구소(IARC)의 GLOBOCAN 2008에 의하면 여성에 있어서 유방암은 발병률과 사망률이 각각 $38.9 \%, 12.4 \%$ 이고 유방암의
발병률과 유방암으로 인한 사망률이 빠르게 증가하고 있다고 보고하였다 ${ }^{[1-2]}$. 유방암도 다른 암과 마찬가지 로 초기에 발견했을 경우에는 생존율이 매우 높지만 병기가 오래될수록 생존율이 떨어진다 ${ }^{[3]}$.

유방암의 영상검사방법에는 Mammography, 유방초 
음파, 자기공명영상, 핵의학 검사 등이 있다. 이 중에 서 기본검사인 Simple X-ray을 이용한 mammography는 물질의 엑스선 흡수도(absorption) 차이에 의한 대비영 상(contrast image)로부터 병변을 감별하고 진단한다[3]. 엑스선의 에너지가 높으면 엑스선이 피사체(object)를 통과하여 영상의 대조도를 떨어뜨리고 엑스선의 에너 지가 낮으면 영상의 대조도는 증가시키지만 엑스선이 피사체에 흡수되어 환자의 피폭선량을 증가시킨다. 그 러므로 적정한 엑스선 에너지는 영상의 질과 피폭선 량에 영향을 미치는 매우 중요한 요소이다. X-선 선질 에 영향을 미치는 것은 관전압, 관전류, 시간, 엑스선 관의 양극물질 종류, 부가필터의 물질 종류와 두께 등 이 있다 ${ }^{[4]}$. 단순엑스선을 이용한 유방촬영장치의 타겟 물질로 몰리브덴(Mo)이나 로듐(Rh)이 이용되었으나 최 근 텅스텐(W)을 이용하는 유방촬영장치가 개발되어 환자의 진료에 이용되고 있다 ${ }^{[5-7]}$.

본 논문에서는 새로운 양극물질을 사용하는 유방촬 영 장치의 도입에 따라 방사선 선질이 다양해진 유방촬 영장치의 영상품질관리와 환자선량관리을 위하여 유방 촬영장치의 타겟 물질에 따른 에너지스펙트럼을 시뮬 레이션하고 팬텀 영상의 화질을 비교하였다.

\section{II. 재료 및 방법}

\section{1. 유방촬영장치}

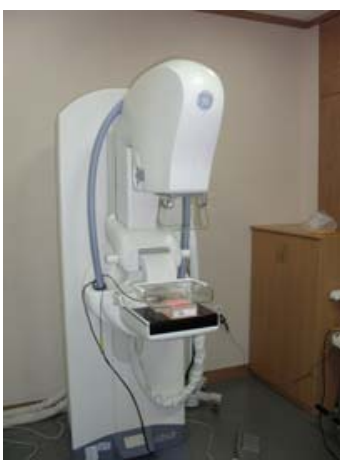

(a) Senographe DS Acquisition (GE Healthcare, USA)

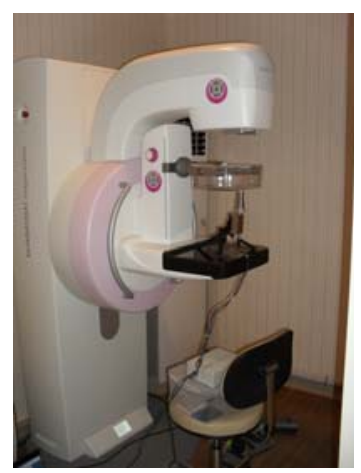

(b) MAMMOMAT Inspiration (SIEMENS, Germany)
Fig. 1. Digital mammography
MAMMOMAT Inspiration (SIEMENS, 독일)의 타깃 은 몰리브덴(Mo)과 텅스텐(W)이고 부가필터는 몰리브 덴(Mo)과 로듐 $(\mathrm{Rh})$ 이다. Senographe DS Acquisition (GE Healthcare, 미국)은 타깃은 몰리브덴(Mo)과 텅스텐(Rh) 이고 부가필터는 몰리브덴(Mo)과 로듐(Rh)이다(그림1).

\section{2. 스펙트럼 시뮬레이션}

유방촬영 X-선 에너지 스펙트럼은 인터넷 싸이트 (https://w9.siemens.com/cms/oemproducts/Home/X-rayT oolbox/spektrum/Pages/MamIn.aspx)에서 제공하는 18 $\mathrm{kV}$ 에서 $40 \mathrm{kV}$ 까지 에너지범위를 갖고 있는 엑스선 에 너지 스펙트럼 시뮬레이션 프로그램을 이용하였다(그 림 2). 이 프로그램은 양극물질의 종류, 관전압, Air kerma, 부가필터의 종류와 두께, 촬영거리를 입력하면 엑스선 광자를 에너지별로 보여준다.

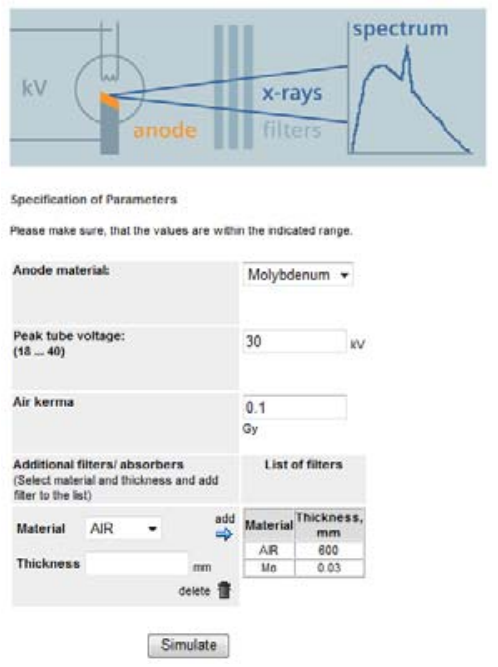

Fig. 2. X-ray energy spectrum simulation program

\section{3. 팬텀}

유방 팬텀의 상부는 각 직경이 $1.56,1.12,0.89,0.75$, $0.54,0.40 \mathrm{~mm}$ 인 나일론 섬유(nylon fiber)와 직경이 $0.54,0.40,0.32,0.24,0.16 \mathrm{~mm}$ 인 산화알루미늄(Al2O3), 그리고 직경이 $2.00,1.00,0.75,0.50,0.25 \mathrm{~cm}$ 인 종괴 (Masses)가 들어있다(그림 3의 상단). 유방 팬텀의 하부 아크릴판 하나의 크기는 가로 $12 \mathrm{~cm}$, 세로 $10 \mathrm{~cm}$, 두께 $1 \mathrm{~cm}$ 이고 부피 $120 \mathrm{~cm} 3$, 질량 $151.08 \mathrm{~g}$, 밀도 약 1.259 
$\mathrm{g} / \mathrm{cm}^{3}$ 이다(그림 3 의 하단). 유방 팬텀의 상부와 하부 아크릴 팬텀 1 개에서 7 개까지 증가시키면서 촬영한 영 상으로부터 섬유소, 석회화 알갱이, 종괴, 유방 팬톰 사진의 광학농도, 아크릴 원판에 의한 대조도로 화질 을 평가하고 비교하였다.

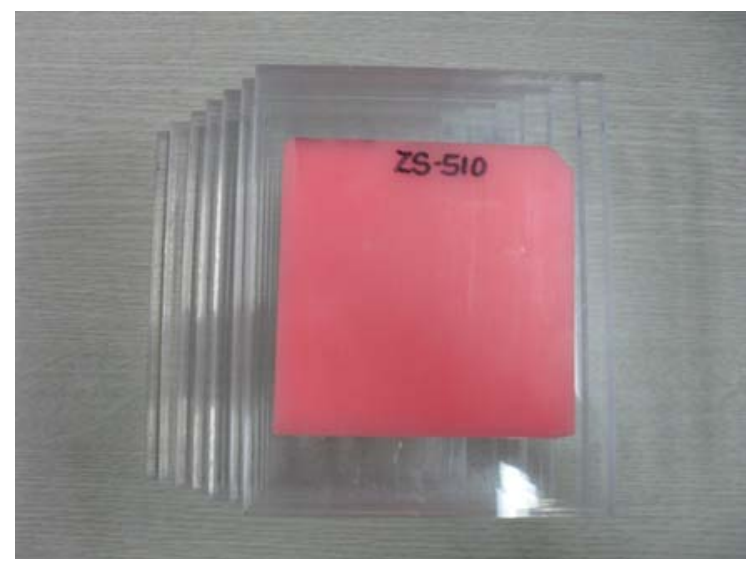

Fig. 3. Mammography phantom; 6 fibers, 5 groups of specks, 5 masses and acrylic plate size; width $12 \mathrm{~cm}$, height $10 \mathrm{~cm}$, thickness $1 \mathrm{~cm}$

III. 결과

\section{1. 스펙트럼 시뮬레이션}

엑스선 선질을 표현하는 방법은 평균에너지, 스펙 트럼 분해능, 반가층 및 동질계수 등 4가지가 있다. 엑 스선의 선원과 검출기(전리함)의 중간에 흡수재를 설 치하고 선량을 측정하여 반가층을 결정하는 방법은 선질 측정 및 확인에 가장 일반적으로 이용되고 있으 나 빔에 대해 얻을 수 있는 정보가 한정적이라는 단점 을 갖는다. 스펙트럼 측정의 경우 별도의 측정장치가 필요하고, 측정결과에 대한 추가적인 처리가 필요하지 만 선질을 표현하는데 사용하는 4가지 인자에 대한 정 보를 모두 확인할 수 있다는 장점을 갖는다.

유방촬영장치의 타겟 물질에 따른 에너지스펙트럼 을 시뮬레이션 결과 $\mathrm{Mo} / \mathrm{Mo}, \mathrm{Rh} / \mathrm{Rh}$ 는 비교적 선에너 지에 가까웠고 이러한 결과는 필터에서 저에너지 뿐 만 아니라 고에너지 부분도 흡수하기 때문이다. $\mathrm{W} / \mathrm{Rh}$ 는 연속스펙트럼 나타났고 필터에서 대부분의
저에너와 고에너지 일부를 흡수하였다(그림 4).

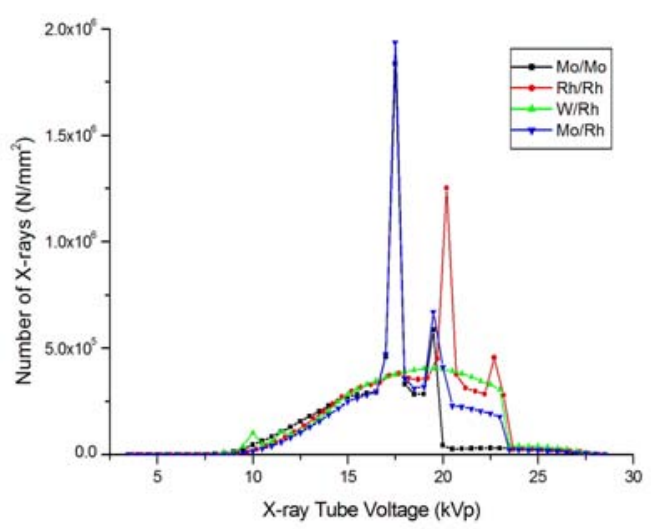

Fig. 4. $28 \mathrm{kVp}$ X-ray energy spectrum used in Monte Carlo calculation

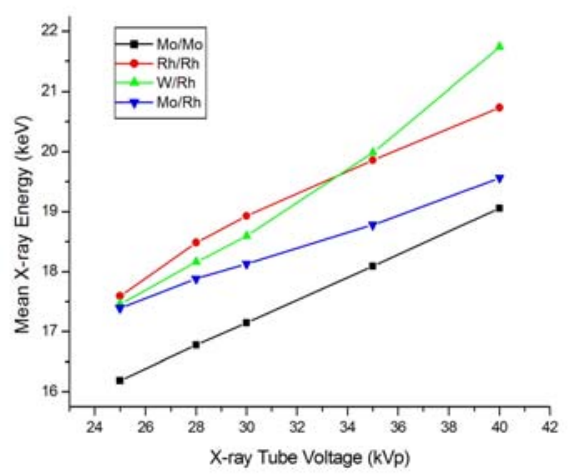

Fig. 5. Mean $\mathrm{X}$-ray energy according to $\mathrm{X}$-ray tube peak voltage and target/filter

\section{2. 평균에너지}

타깃/필터와 엑스선 관전압에 따른 평균에너지의 크기는 $33.5 \mathrm{kVp}$ 까지는 $\mathrm{Mo} / \mathrm{Mo}, \mathrm{Mo} / \mathrm{Rh}, \mathrm{W} / \mathrm{Rh}, \mathrm{Rh} / \mathrm{Rh}$ 순으로 나타났고 $33.5 \mathrm{kVp}$ 이상에서는 $\mathrm{Mo} / \mathrm{Mo}, \mathrm{Mo} / \mathrm{Rh}$, $\mathrm{Rh} / \mathrm{Rh}, \mathrm{W} / \mathrm{Rh}$ 순으로 나타났다(그림 5).

\section{3. 평균에너지}

$\mathrm{Mo} / \mathrm{Mo}$ 을 이용하고 두께가 $1 \mathrm{~cm}$ 유방 팬텀에서 나 일론 섬유(nylon fiber)는 6 개중에서 5 개, 산화알루미늄 
$\left(\mathrm{Al}_{2} \mathrm{O}_{3}\right)$ 는 5 개중에서 4.3 개, 종괴(Masses)는 5 개중에서 5 개 관찰 가능하였다. $\mathrm{Rh} / \mathrm{Rh}$ 와 $\mathrm{W} / \mathrm{Rh}$ 을 이용하고 두께 가 $1 \mathrm{~cm}$ 유방 팬텀에서 나일론 섬유(nylon fiber)는 6개 중에서 5 개, 산화알루미늄 $\left(\mathrm{Al}_{2} \mathrm{O}_{3}\right)$ 는 5 개중에서 4 개, 종 괴(Masses)는 5 개중에서 4 개 관찰 가능하였다. 두께가 $1 \mathrm{~cm}$ 유방 팬텀에서는 타깃이 $\mathrm{Mo} / \mathrm{Mo}$ 일 때보다 $\mathrm{Rh} / \mathrm{Rh}$ 와 $\mathrm{W} / \mathrm{Rh}$ 일 때 섬유소 관찰이 용이함을 알 수 있다.

$\mathrm{Mo} / \mathrm{Mo}$ 을 이용하고 두께가 $6 \mathrm{~cm}$ 유방 팬텀에서 나 일론 섬유(nylon fiber)는 6 개중에서 3 개, 산화알루미늄 (Al2O3)는 5개중에서 2개, 종괴(Masses)는 5 개중에서 3 개 관찰 가능하였다. $\mathrm{Rh} / \mathrm{Rh}$ 와 W/Rh을 이용하고 두께 가 $6 \mathrm{~cm}$ 유방 팬텀에서 나일론 섬유(nylon fiber)는 6 개 중에서 4 개, 산화알루미늄(Al2O3)는 5 개중에서 3.5 개, 종괴(Masses)는 5 개중에서 4 개 관찰 가능하였다. 두께가 $1 \mathrm{~cm}$ 유방 팬텀에서는 타깃이 $\mathrm{Rh} / \mathrm{Rh}$ 와 $\mathrm{W} / \mathrm{Rh}$ 일 때보 다 $\mathrm{Mo} / \mathrm{Mo}$ 일 때 섬유소 관찰이 용이함을 알 수 있다.

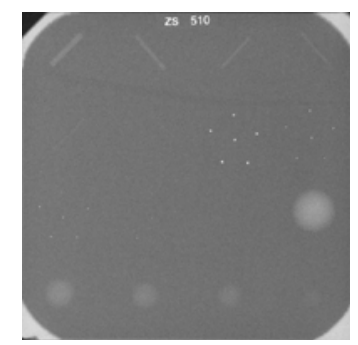

(a) GE Mo/Mo $1 \mathrm{~cm}$

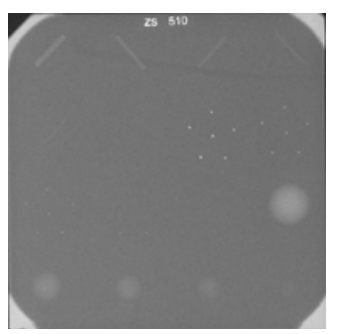

(c) GE Rh/Rh $1 \mathrm{~cm}$

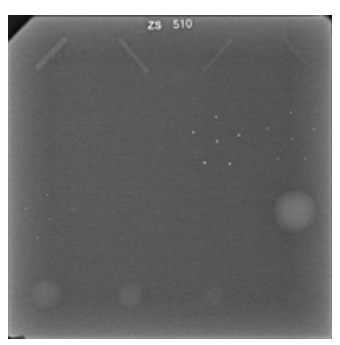

(e) Siemens Mo/Mo $1 \mathrm{~cm}$

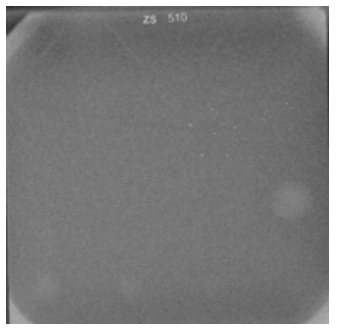

(b) GE Mo/Mo $6 \mathrm{~cm}$

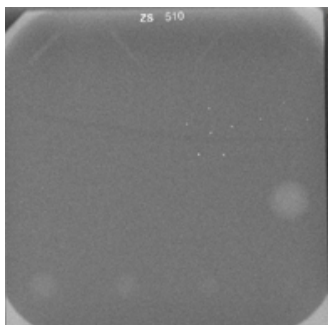

(d) GE Rh/Rh $6 \mathrm{~cm}$

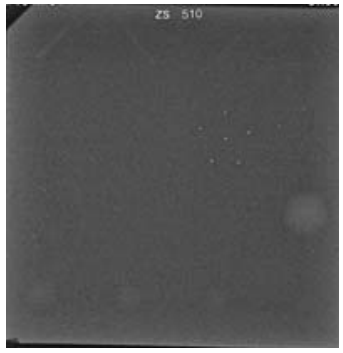

(f) Siemens Mo/Mo $6 \mathrm{~cm}$

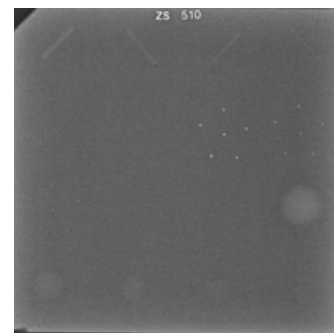

(g) Siemens W/Rh $1 \mathrm{~cm}$

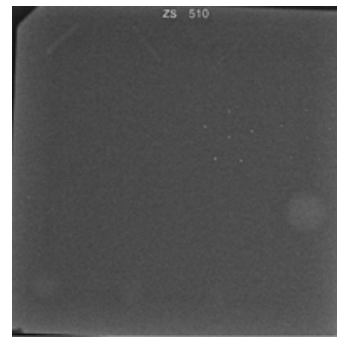

(h) Siemens $R h / R h 6 \mathrm{~cm}$
Fig. 5. Phantom images according to Mo/Mo, Rh/Rh and W/Rh

\section{IV. 결론}

스펙트럼은 $\mathrm{Mo} / \mathrm{Mo}, \mathrm{Rh} / \mathrm{Rh}$ 는 선스펙트럼과 유사하 였고 $\mathrm{W} / \mathrm{Rh}$ 는 연속스펙트럼에 가까웠다. 평균에너지 는 $33.5 \mathrm{kVp}$ 이하에서는 $\mathrm{Rh} / \mathrm{Rh}$ 이 $33.5 \mathrm{kVp}$ 이상에서 $\mathrm{W} / \mathrm{Rh}$ 이 높았다. 팬텀 영상의 화질은 두께가 $1-3 \mathrm{~cm}$ 에 서 $\mathrm{Mo} / \mathrm{Mo}$ 가 4-7에서 $\mathrm{Rh} / \mathrm{Rh}$ 와 $\mathrm{W} / \mathrm{Rh}$ 이 유리하였다. 향후 필터, 팬텀, 관전압의 조합을 미세 변화시켜 화질 의 변화를 연구하고 디지털 센서 등 화질에 미치는 여 러 요소에 대한 추가 연구 필요하다.

\section{감사의 글}

이 논문은 2011년 한국연구재단 원자력장학생 지원 사업 및 교육과학기술부의 재원으로 시행하는 한국과 학재단의 연구지원프로그램으로 지원받았습니다. (연 구과제코드: 2011-0010310)

\section{참고문헌}

[1] Gswlobocan 2008

(http://globocan.iarc.fr/factsheets/populations/factsheet.asp?uno=900)

[2] 송병주, 손병호, 박찬흔,강성수, 김석원, "2006-2008 유방암 백서”, 한국유방암학회, 1, 1-25, 2008.

[3] 송병주, 손병호, 박찬흔,강성수, 김석원, "2006-2008 유방암 백서”, 한국유방암학회, 1, 1-25, 2008.

[4] 이철영, "Mammography X-선 선량평가 사업", 식품의약품안전청, 1, 1-80, 2005.

[5] Philipp Bernhardt, Thomas Mertelmeier and Martin Hoheisel, "X-ray spectrum optimization of full-field digital mammography: Simulation and phantom", study", Medical Physics, 33, 4337-4349, 2006.

[6] P BALDELLI, N PHELAN and G EGAN, "Investigation of the 
effect of anode/filter materials on the dose and image quality of a digital mammography system based on an amorphous selenium flat panel detector", The British Journal of Radiology, 33, 290-295, 2010.

[7] M. Säbel, H. Aichinger, "Recent developments in breast imaging”, Physics in Medicine and Biology, 41, 315-368, 1996. 